Table 1. Comparison of characteristics of seropositive and seronegative PsA patients

\begin{tabular}{llll}
\hline Items & $\begin{array}{l}\text { Group 1 } \\
\text { Seropositive patients }(\mathrm{n}=22)\end{array}$ & $\begin{array}{l}\text { Group 2 } \\
\text { Seronegative patients } \\
(\mathrm{n}=58)\end{array}$ & p-value \\
\hline Age (years) & $51.1+/-9.45$ & $50.7+/-15.8$ & 0.9 \\
Sex ratio M/F & 0.29 & 1.14 & 0.013 \\
Age onset (years) & $43.5+/-10.4$ & $37.4+/-16.5$ & 0.123 \\
Skin involvement $(\%)$ & 100 & 50 & 0.009 \\
Bone erosions (\%) & 81.1 & 56.9 & $<0.001$ \\
Response to treatment (\%) & 70.58 & 51.14 & $<0.001$ \\
\hline
\end{tabular}

erosions in addition to signs of destruction was in $81.8 \%$ of cases. The response to treatment with (corticosteroids / NSAIDs / DMARDs) was partial in $70.58 \%$. In group 2, the mean age was 50.7 years $(+/-15.8)$. The sex ratio $\mathrm{M} / \mathrm{F}$ was 1.14 , the mean age of onset was 37.4 years $(+/-16.5)$, the mean duration of disease was 13.3 years $(+/-9.5)$. Skin involvement was present in $50 \%$ of patients. Polyarticular involvement was present in all cases, axial involvement was present in $67.24 \%$ of cases and enthesitis in $56.9 \%$ of cases. All patients were HLA B 27 negative. The presence of X-ray and / or ultrasound bone erosions in addition to signs of destruction was in $56.9 \%$ of cases. The response to treatment with (corticosteroids / NSAIDs / DMARDs) was partial in $57.14 \%$

Conclusion: The presence of anti-CCP according to several studies is linked to the presence of deformities, dactylites and radiological erosions $(1,2)$. In our series, seropositivity was accompanied by the erosive nature of the destruction, as well as a tendency to resistance to treatment.

REFERENCES:

[1] Kim KY, Lee YH. Anti-cyclic citrullinated peptide antibody in psoriatic arthritis: a meta-analysis of its frequency and association with clinical features. $Z$ Rheumatol. mai 2020;79(4):397-403.

[2] Hagiwara S, Tsuboi H, Terasaki T, Terasaki M, Toko H, Shimizu M, et al. Association of anti-cyclic citrullinated peptide antibody with clinical features in patients with psoriatic arthritis. Modern Rheumatology. 3 mars 2020;30(2):365-72.

Disclosure of Interests: None declared.

DOI: 10.1136/annrheumdis-2021-eular.2958

\section{POS1078 CURRENT REGISTRIES IN PSA DO NOT WELL REFLECT THE PROFILES OF PATIENTS WITH PSA BECAUSE THEY ORIGINATE IN SIMILAR COUNTRIES: A SYSTEMATIC LITERATURE REVIEW OF 27 REGISTRIES, OR 16183 PATIENTS}

G. S. Moysidou ${ }^{1}$, K. Aouad ${ }^{1}$, A. Rakotozafiarison 1 , B. Fautrel ${ }^{1}$, L. Gossec ${ }^{1}$ ${ }^{1}$ Sorbonne Université - INSERM; AP-HP, Pitié Salpêtrière Hospital, Rheumatology department, Paris, France

Background: Psoriatic arthritis (PsA) is a multidimensional inflammatory disease with a great geographic variability and a global average prevalence estimated at 133 every

100,000 subjects according to a recent systematic review and meta-analysis (1). Registries and cohorts reflect more closely real-world data than randomized controlled trials (RCTS) and may indicate ongoing interest of each country on PsA. Objectives: The purpose of this study is to assess how recent registries and PsA related cohorts reflect its worldwide prevalence.

Methods: A systematic literature review was performed in Pubmed Medline (PROSPERO

CRD42020175745) to identify all articles reporting on either registries or longitudinal cohorts in PsA, published between 2010 and March 2020. Registries centered on drugs or not PsA-specific, trials and long term extension studies were excluded. The data collection comprised registries' and cohorts' originating countries, patient characteristics and the clinical outcome measures reported. Statistics were descriptive.

Results: Of 673 articles, 73 were relevant for analysis, corresponding to 27 registries or PsA specific cohorts, with the participation of 30 countries. The overall number of patients was 16,183 with a mean of 599 per study. Overall, $50.1 \%$ were men, weighted mean age was 50,6 years and weighted mean disease duration was 6.9 years.

Most of the registries were based in Europe (67\%) or North America (26\%) whereas Africa was underrepresented (Figure 1). USA was the most represented country participating in 6 registries. Mean age and mean disease duration were shorter in international registries (Table 1). Caspar diagnostic criteria were the most frequently used, mainly in the national registries $(86,4 \%)$, whereas the use of diagnostic criteria was more heterogenous in the international registries. Conclusion: Recent registries and PsA specific cohorts do not cover the worldwide spectrum of the disease.

\section{REFERENCES:}

[1] Scotti L, Franchi M, Marchesoni A, Corrao G. Prevalence and incidence of psoriatic arthritis: A systematic review and meta-analysis. Semin Arthritis Rheum. 2018 Aug;48(1):28-34

Table 1. Description of 27 ongoing PsA registries or PsA cohorts, comparing nationwide and international registries

\begin{tabular}{lll}
\hline & NATIONWIDE & INTERNATIONAL \\
& REGISTRIES (N=22) & REGISTRIES (N=5) \\
\hline WOMEN (\%) & 49,4 & 50,8 \\
MEAN AGE, WEIGTHED (YEARS) & 52,32 & 48,09 \\
$\begin{array}{c}\text { MEAN DISEASE DURATION, WEIGHTED } \\
\quad 8,59\end{array}$ & 5,86 \\
$\begin{array}{l}\text { (YEARS) } \\
\text { CASPAR DIAGNOSTIC CRITERIA (\%) }\end{array}$ & 86,4 & 40 \\
\hline
\end{tabular}

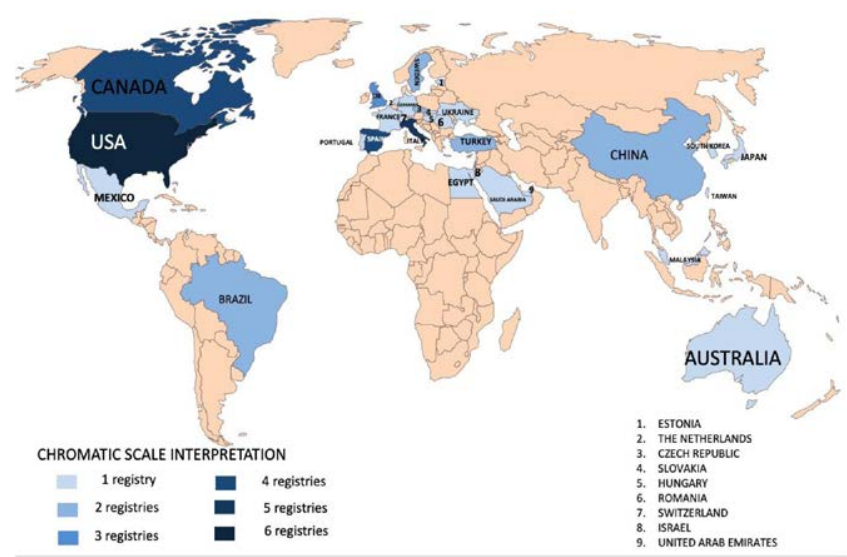

Figure 1. Geographical distribution of PsA registries

Disclosure of Interests: None declared.

DOI: 10.1136/annrheumdis-2021-eular.3097

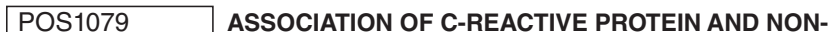 STEROIDAL ANTI-INFLAMMATORY DRUGS WITH CARDIOVASCULAR EVENTS IN PATIENTS WITH PSORIATIC ARTHRITIS: A TIME-DEPENDENT Cox REGRESSION ANALYSIS}

S. H. M. Lam ${ }^{1}$, H. So ${ }^{1}$, I. T. Cheng ${ }^{1}$, E. LI ${ }^{1}$, P. C. Wong ${ }^{1}$, T. K. LI ${ }^{1}$, A. P. W. Lee ${ }^{1}$, L. S. Tam ${ }^{1} .{ }^{1}$ The Chinese University of Hong Kong, Department of Medicine and Therapeutics, Sha Tin, Hong Kong (SAR)

Background: Psoriatic arthritis (PsA) is associated with accelerated atherosclerosis due to underlying inflammation. Whether inflammatory burden and drugs used to suppress inflammation over time are associated with cardiovascular (CV) events remains unclear.

Objectives: This study aims to examine the time-varying effect of C-reactive protein (CRP) levels and the use of drugs including non-steroidal anti-inflammatory drugs (NSAIDs) on the risk of CV events independent of traditional CV risk factors in PsA patients.

Methods: A retrospective cohort analysis was performed in patients with PsA who were recruited from 2008 to 2015 and followed till the end of 2019. The outcome was occurrence of a first CV event. Framingham risk score (FRS) was used to quantify the traditional CV risk. Cox proportional hazard models with time-varying CRP levels and drugs used were analyzed to identify the risk factors for CV events in PsA patients.

Results: 200 patients with PsA (median age: 47.5[40.0 - 56.0]; male: 119 [59.5\%]) were recruited (Table 1. next page). After a mean follow-up of $8.8 \pm 3.8$ years, $30(15 \%)$ patients developed a first CV event. The Kaplan-Meier survival analysis indicated a significant difference in the $\mathrm{CV}$ event-free survival between patients with and without CRP level $>3 \mathrm{mg} / \mathrm{L}$ (Figure $1 \mathrm{~A}$ ) and an inverse relationship between time-varying NSAIDs exposure and CV event-free survival (Fig ure 1B). The multivariable Cox regression model showed that time-varying CRP level (HR 1.02, 95\% Cl 1.00 to 1.04) and NSAIDs exposure (HR 0.30, 95\% Cl 0.15 to 0.95 ) were significantly associated with $\mathrm{CV}$ events after adjusting for baseline FRS (HR 5.04, 95\% Cl 1.83 to 13.85). 
Table 1. Baseline demographic and clinical characteristics, cardiovascular risk factors and treatments received.

\begin{tabular}{|c|c|c|c|c|c|c|c|}
\hline Variables & $\begin{array}{l}\text { All patients } \\
n=200 \\
\text { median (IQR) or } n(\%)\end{array}$ & $\begin{array}{l}\text { CVD -ve, } \\
\mathrm{n}=170 \\
\text { median (IQR) } \\
\text { or } \mathrm{n}(\%)\end{array}$ & $\begin{array}{l}\text { CVD +ve, } \\
\mathrm{n}=30 \\
\text { median (IQR) } \\
\text { or } \mathrm{n}(\%)\end{array}$ & $p$-value & $\begin{array}{l}\text { NSAID -ve, } \mathrm{n}=61 \\
\text { median (IQR) } \\
\text { or } \mathrm{n}(\%)\end{array}$ & $\begin{array}{l}\text { NSAID +ve, } n=139 \\
\text { median (IQR) or } n(\%)\end{array}$ & $p$-value \\
\hline Male, n (\%) & $119(59.5 \%)$ & $100(58.6 \%)$ & $19(63.3 \%)$ & 0.228 & $39(63.9 \%)$ & $80(57.6 \%)$ & 0.397 \\
\hline Age, years & $47.5(40.0-56.0)$ & $46.5(37.7-54.0)$ & $57.0(45.3-65.8)$ & $<0.001^{\star}$ & $49.0(44.0-56.5)$ & $46.0(38.0-54.8)$ & 0.176 \\
\hline Disease duration, years & $4.3(1.8-7.9)$ & $4.1(1.7-7.0)$ & $6.0(2.1-8.6)$ & 0.066 & $4.6(1.5-8.7)$ & $4.3(1.9-7.3)$ & 0.393 \\
\hline Diabetes, $\mathrm{n}(\%)$ & $45(22.5 \%)$ & $30(17.6 \%)$ & $15(50.0 \%)$ & $<0.001^{*}$ & $10(16.4 \%)$ & $35(25.2 \%)$ & 0.171 \\
\hline Hypertension, n (\%) & 68 (34.0\%) & $46(27.1 \%)$ & 22 (73.3\%) & $<0.001^{*}$ & 21 (34.4\%) & 47 (33.9\%) & 0.933 \\
\hline CRP, mg/L & $4.9(1.7-12.6)$ & $4.2(1.5-12.0)$ & $11.3(2.4-19.6)$ & $0.035^{\star}$ & $5.5(1.7-15.1)$ & $7.2(1.4-15.8)$ & 0.770 \\
\hline $\mathrm{ESR}, \mathrm{mm} / \mathrm{hr}$ & $21(10.0-38.0)$ & $20(9-35)$ & $31(14-60)$ & $0.038^{*}$ & $21(7-33)$ & $21(11-43)$ & 0.291 \\
\hline Systolic blood pressure, $\mathrm{mmHg}$ & $125(115-140)$ & $124(115-137)$ & $144(129-160)$ & $<0.001^{*}$ & $123(118-137)$ & $125(115-141)$ & 0.889 \\
\hline Diastolic blood pressure, $\mathrm{mmHg}$ & $78(70-85)$ & $78(70-84)$ & $82(72-90)$ & 0.199 & $78(72-86)$ & $78(70-85)$ & 0.697 \\
\hline FRS & $8.4(4.0-17.0)$ & $7.5(3.3-14.0)$ & $19.6(13.4-43.0)$ & $<0.001^{*}$ & $7.9(3.5-15.5)$ & $8.7(4.2-17.1)$ & 0.885 \\
\hline Lipid-lowering drugs, $n$ (\%) & $30(15.0 \%)$ & $25(14.7 \%)$ & $5(16.7 \%)$ & 0.782 & $9(14.8 \%)$ & $21(15.1 \%)$ & 0.949 \\
\hline MTX, n (\%) & 99 (49.5\%) & 81 (47.6\%) & $18(60.0 \%)$ & 0.212 & $25(41.0 \%)$ & $74(53.2 \%)$ & 0.111 \\
\hline bDMARDs, n (\%) & $17(8.5 \%)$ & $13(7.6 \%)$ & $4(13.3 \%)$ & 0.303 & $6(9.8 \%)$ & $11(7.9 \%)$ & 0.654 \\
\hline NSAIDs, n (\%) & $139(69.2 \%)$ & $119(70.0 \%)$ & $20(66.7 \%)$ & 0.715 & N/A & N/A & N/A \\
\hline Steroid, n (\%) & $2(1.0 \%)$ & $2(1.2 \%)$ & $0(0 \%)$ & 1.000 & $1(1.6 \%)$ & $1(0.7 \%)$ & 0.518 \\
\hline
\end{tabular}

*statistically significant at $p \leq 0.05 C V D+v e$, patients who developed cardiovascular events during subsequent follow-up;CVD-ve, patients who did not developed cardiovascular events during subsequent follow-up;NSAIDs, nonsteroidal anti-inflammatory drugs; CRP, C-reactive protein; ESR, erythrocyte sedimentation rate; FRS, Framingham Risk Score; MTX, methotrexate; bDMARDs, biological disease-modifying antirheumatic drugs.

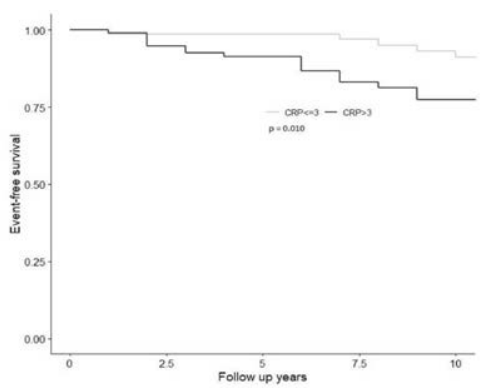

Figure IA

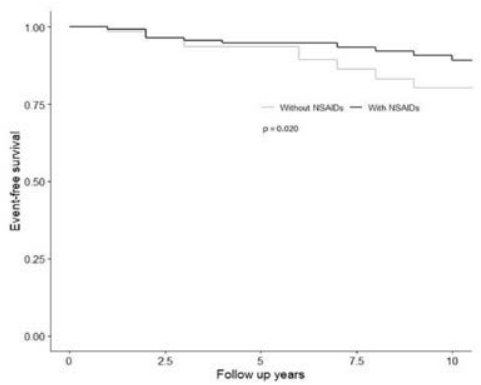

Figure 1B

Figure 1. Kaplan-Meier curves showing the cardiovascular event-free survival between patients with A) CRP 3 mg L and CRP 3 mg L; B) treated with NSAIDs and without NSAIDs use during their follow-up intervals.

Conclusion: Increased inflammatory burden as reflected by elevated CRP level was associated with increased risk of CV events, while the risk was significantly reduced with NSAIDs use in PsA patients.

Disclosure of Interests: None declared.

DOI: 10.1136/annrheumdis-2021-eular.3118

\section{POS1080 \\ HYPERLIPIDEMIA IN PSORIATIC DISEASE: HIGHER PREVALENCE IN PSORIATIC ARTHRITIS AND INVERSE ASSOCIATION WITH SYSTEMIC THERAPY}

R. Queiró Silva ${ }^{1}$, E. Pardo Campo ${ }^{1}$, S. Fernández ${ }^{1}$, L. Arboleya Rodríguez ${ }^{1}$, I. Zapico ${ }^{1}$, F. Jirout ${ }^{1} .{ }^{1}$ Hospital Universitario Central de Asturias, Rheumatology, OVIEDO, Spain

Background: Although the evidence that testifies to a higher prevalence of cardiometabolic risk factors in psoriatic disease is robust, there are not too many studies that have analyzed which disease traits are associated with these risk factors both in psoriasis and psoriatic arthritis ${ }^{1}$.

Objectives: We aimed to analyze the frequency and disease-associated features of hyperlipidemia in psoriatic disease.

Methods: Cross-sectional observational study that included 290 patients with psoriatic arthritis (mean age $54 \pm 12$ years, $54.8 \%$ male, psoriasis average duration $21 \pm 10$ years) and 310 with psoriasis alone (mean age $53 \pm 11.5$ years, $52.9 \%$ male, psoriasis average duration $22 \pm 11$ years). We first analyzed the frequency of this comorbidity and then the factors associated with it using conditional logistic regression. The significant factors in this first model were introduced in a multivariate model using a backward stepwise approach.

Results: Main disease features are depicted in Table 1. A total of 124 patients had hyperlipidemia (20.7\%). Among arthritis patients, 82/290 (28.3\%) had hyperlipidemia, compared with $42 / 310$ (13.5\%) of those with psoriasis alone (OR 2.5 , $95 \% \mathrm{Cl}: 1.7-3.3, p<0.001)$. Hyperlipidemia was independently associated with age [OR $1.07,95 \% \mathrm{Cl}: 1.04-1.11, \mathrm{p}<0.001]$ and systemic therapy [OR $0.4,95 \% \mathrm{Cl}$ $0.17-0.89, p=0.026]$.

Conclusion: Hyperlipidemia is common in psoriatic disease, but much more among arthritis patients. This comorbid factor seems to go in parallel with increasing age. There is an inverse association between systemic treatment and hyperlipidemia that should be endorsed with well-designed longitudinal studies. REFERENCES:

[1] Puig L. Cardiometabolic comorbidities in psoriasis and psoriatic arthritis. Int J Mol Sci 2018; 19: 58

Table 1. Disease characteristics of both subpopulations

\begin{tabular}{|c|c|c|c|}
\hline Variable & $\begin{array}{l}\text { PsA } \\
n=290\end{array}$ & $\begin{array}{l}\text { Psoriasis } \\
n=310\end{array}$ & $\mathrm{p}$-values \\
\hline Age $(y r \pm S D)$ & $54 \pm 12$ & $53 \pm 11.5$ & NS \\
\hline Age at psoriasis onset $(\mathrm{yr} \pm \mathrm{SD})$ & $32 \pm 16$ & $31 \pm 14.2$ & NS \\
\hline Age at arthritis onset $(\mathrm{yr} \pm \mathrm{SD})$ & $46 \pm 14$ & & NS \\
\hline Duration of psoriasis $(\mathrm{yr} \pm \mathrm{SD}$ ) & $21 \pm 10$ & $22 \pm 11$ & NS \\
\hline Duration of arthritis $(\mathrm{yr} \pm \mathrm{SD})$ & $11 \pm 7.2$ & & NS \\
\hline Male gender $(n, \%)$ & $159(54.8)$ & $164(52.9)$ & NS \\
\hline Primary education $(\mathrm{n}, \%)$ & $145(50)$ & $148(47.7)$ & NS \\
\hline Secondary education (n, \%) & 79 (27.2) & $87(28.1)$ & NS \\
\hline University degree $(n, \%)$ & $66(22.8)$ & $235(24.2)$ & NS \\
\hline Plaque psoriasis (n, \%) & $250(86.2)$ & $272(87.7)$ & NS \\
\hline Nail disease $(n, \%)$ & $122(42.1)$ & $110(35.5)$ & NS \\
\hline Psoriasis in $\geq 3$ body areas (n, \%) & $130(45)$ & $155(50)$ & $<0.05$ \\
\hline Family history of psoriasis $(n, \%)$ & $130(45)$ & $136(44)$ & NS \\
\hline Family history of PsA $(n, \%)$ & $44(15.2)$ & $15(4.8)$ & \\
\hline PASI & $6.5 \pm 4.3$ & $6.8 \pm 3.5$ & \\
\hline Oligoarthritis (n, \%) & $122(42.1)$ & & \\
\hline Polyarthritis (n, \%) & $81(28)$ & & \\
\hline Axial disease (n, \%) & $17(5.8)$ & & \\
\hline Mixed pattern (n, \%) & $70(24.1)$ & & \\
\hline Dactylitis (n, \%) & $87(30)$ & & \\
\hline DIP joint disease (n, \%) & $72(24.8)$ & & \\
\hline Mutilating arthritis $(\mathrm{n}, \%)$ & $5(1.7)$ & & \\
\hline Erosive disease $(\mathrm{n}, \%)$ & $58(20)$ & & \\
\hline $\mathrm{HAQ}($ mean $\pm \mathrm{SD})$ & $0.74 \pm 0.32$ & & \\
\hline${ }^{*} \mathrm{BASDAl}($ mean $\pm \mathrm{SD})$ & $3.64 \pm 2.12$ & & \\
\hline Pain VAS (mean \pm SD) & $4.09 \pm 2.64$ & & \\
\hline HLA-B*27 (n, \%) & $52(17.9)$ & & \\
\hline HLA-C*06 (n, \%) & $112(38.6)$ & $124(40)$ & NS \\
\hline $\operatorname{NSAID}(\mathrm{n}, \%)$ & $72(24.8)$ & $47(15.2)$ & NS \\
\hline Glucocorticoids (n, \%) & $34(11.7)$ & $15(4.8)$ & NS \\
\hline $\operatorname{MTX}(n, \%)$ & $189(65.2)$ & $128(41.3)$ & $<0.05$ \\
\hline Biologics (n, \%) & $128(44.1)$ & $132(42.6)$ & NS \\
\hline
\end{tabular}

SD, standard deviation; PsA, psoriatic arthritis; PASI, psoriasis area and severity index; DIP, distal interphalangeal joint; $H A Q$, Health Assessment Questionnaire; BASDAI, bath ankylosing spondylitis disease activity index; VAS, visual analog scale; NSAID, non-steroidal anti-inflammatory drugs. MTX, methotrexate. ${ }^{*}$ Only in patients with axial disease

Disclosure of Interests: None declared.

DOI: 10.1136/annrheumdis-2021-eular.3170 